\title{
Interaction effects of response inhibition and affectivity in tobacco craving
}

\author{
Nelson Bruno de Almeida Cunha(D', Carlos Eduardo Martínez Munguía(D) \\ I Centro de Estudios e Investigaciones en Comportamiento, Universidad de Guadalajara, Guadalajara, México.
}

\section{RESUMEN}

Introducción: Los modelos de dependencia a la nicotina indican la influencia de la impulsividad y la afectividad en las conductas de consumo de tabaco. Sin embargo, es necesario que estudios con mayor validez ecológica sean llevados a cabo a fin de dilucidar cómo la impulsividad y la afectividad se articulan para provocar el craving. Objetivo: Evaluar los efectos de interacción de la inhibición de respuestas y la afectividad en el craving por tabaco. Método: Este estudio fue llevado a cabo con 90 fumadores, quienes fueron divididos en dos grupos, de acuerdo con su desempeño en una tarea paramétrica de Go/No-Go (mayor y menor nivel de inhibición de respuestas). El craving provocado por señales fue medido con respuestas fisiológicas y autoreporte, antes y después de una manipulación afectiva agradable o desagradable. Resultados: Los análisis de moderación sugieren que la impulsividad y el afecto desagradable tienen efectos combinados en el craving autoreportado y relacionado a la conductancia eléctrica de la piel. El nivel de inhibición de respuestas parece incrementar el craving por tabaco, pero es independiente del afecto agradable. Discusión y conclusiones: La afectividad es un factor fundamental para la comprensión de la relación entre impulsividad y craving por tabaco. El afecto desagradable es uno de los detonantes del deseo de fumar, especialmente para aquellos individuos más impulsivos, quienes tienen una percepción exagerada de los efectos del tabaco para aliviar experiencias desagradables. Es esencial entrenar técnicas de control de estímulos afectivos negativos, especialmente para aquellos individuos con menor capacidad de inhibición de respuestas.

Palabras clave: inhibición de respuestas, afecto desagradable, afecto agradable, ansia, fumadores.

\begin{abstract}
Introduction: Models of nicotine dependence indicate the influence of impulsivity and affectivity in smoking behaviors. However, it is necessary that studies with higher ecological validity are carried out in order to elucidate how impulsivity and affectivity articulate to provoke tobacco craving. Objective: To evaluate the interaction effects of response inhibition and affectivity in tobacco craving. Method: The study was carried out with 90 smokers, who were divided into two groups, according to their performance on a parametric Go/No-Go task (higher and lower level of response inhibition). Cue-elicited craving was measured by physiologic responses and self-report, before and after a pleasant or unpleasant affectivity manipulation. Results: Moderation analysis suggests that response inhibition and unpleasant affect have combined effects in self-report and skin conductance related to tobacco craving. Response inhibition levels seem to increase tobacco craving, but they are independent of pleasant affect. Discussion and conclusions: Affectivity is a fundamental factor in comprehending the relationship between response inhibition and craving for tobacco. The unpleasant affect is one of the triggers for the desire to smoke, especially for those more impulsive individuals, which have an exaggerated perception of tobacco effect in alleviating unpleasant experiences. It is essential to train techniques to control negative affect stimuli, especially in those individuals with less capacity to inhibit responses.
\end{abstract}

Keywords: response inhibition, unpleasant affect, pleasant affect, craving, smokers.

\section{Corresponding author:}

Nelson Bruno de Almeida Cunha. Centro de Estudios e Investigaciones en Comportamiento, Universidad de Guadalajara, Francisco de Quevedo \# 180, Col. Arcos Vallarta, cp 44130, Guadalajara, Jalisco, México. Phone: + 523322741024.

E-mail address: nbruno.dealmeida@alumnos.udg.mx.

Recibido: 20 de enero de 2021

Aceptado: 20 de mayo de 2021

doi: 10.28931/riiad.2021.2.01 


\section{INTRODUCTION}

Recent research suggests that traits associated with appetite and reward-seeking behavior, such as impulsivity, influence regular and experimental tobacco use (Doran \& Tully, 2018; Kale et al., 2018, 2020). This behavioral trait is linked to the severity of cigarette dependence, higher levels of craving after a period of withdrawal, tobacco use to alleviate negative affect, as well as speed up relapses after an attempt to quit smoking (Roys et al., 2016).

The study by Roys et al. (2016) showed that urgency (a facet of impulsivity) is related to cigarette dependence in individuals with moderate and high levels of anhedonia (loss of interest or satisfaction in previously enjoyed activities). However, this relationship only occurs when tolerance, craving, tobacco-related stimuli, and positive reinforcement (such as hedonic sensations) are the reasons for smoking. It is possible to assume that these factors related to the expectation of reinforcement and affective states constitute possible mechanisms that explain the relationship between impulsivity and tobacco consumption.

Borges et al. (2019) conducted a linear regression model to check if negative urgency predicts smoke consumption, employing puff topography. This study was carried out with 124 smokers who participated in an ad-libitum smoking trial, in which the puff volume, duration, velocity, and inter-puff interval were averaged across the smoking session and evaluated at the puff level. The results suggested that puff durations remained elevated throughout a cigarette, and inter-puff intervals decreased at the end of a cigarette for smokers higher in negative urgency. This means that the intensity and desire of consuming tobacco are enhanced under negative affective states by more impulsive users.

Although the literature is consistent about the relationship between impulsive behavior and smoking, there is much weakness in identifying which components underlying impulsivity are related to tobacco. This because there are important divergences regarding the epistemological approach adopted for research on impulsivity in the different areas of knowledge, which has given rise to the acceptance of the multifaceted character of the said construct.

The review done by Strickland \& Johnson (2020) pointed out that impulsivity comprises a collection of distinct and unrelated personality traits and behaviors. The authors argued that the construct of impulsivity must be rejected due to some aspects like the lack of correlation with each other, difficulty of loading them into a single superior latent variable, different neurobehavioral profiles, and others; but instead, it is recommendable to talk about subjacent behaviors of impulsivity. So, for the present study, it was considered more appropriate to investigate response inhibition, as a specific behavior addressed in psychometric tests, rather than impulsivity.

The main methods for measuring response inhibition consider performance on behavioral tasks and self-report. According to Cyders and Coskunpinar (2011), the main advantage of using behavioral tasks over self-report questionnaires is that the former allows evaluating a behavior trend in real-time, using real or hypothetical situations that emerge as impulsive situations. The Go/NoGo Parametric Task (PGNG) proposed by Langenecker et al. (2007) takes into account several factors of behavioral disinhibition and seems to reach cognitive components (like executive functions) that the other tasks are not capable of measuring (Weidacker et al., 2016). The result of this is the possibility of eliminating the floor and ceiling effects of traditional Go/No-Go tasks (Langenecker et al., 2007; Plewnia et al., 2013).

More than impulsive behavior, affective states are related to tobacco consumption. Studies have found evidence that unpleasant affect is predictive of craving and relapse during smoking abstinence, likewise, pleasant affect is predominantly related to craving and motivation to smoke during ad libitum smoking (Bujarski et al., 2015; Heckman, et al., 2013; Karekla et al., 2017; Shiffman et al., 2014).

By assuming craving as a classical conditioning process, in which the signals related to smoking trigger the affectivity linked to the expectations of reinforcement (i.e., hedonic sensations of the substance or relief of withdrawal symptoms), it is possible to argue that individuals high on negative urgency may make rash decisions to consume tobacco in the presence of smoking cues. Papachristou, Nederkoorn, Havermans et al. (2013) investigated the effects of response inhibition on the cue-elicited craving for alcohol, and his regression model indicated that the response inhibition predicts craving. One possible explanation for this phenomenon is that, during abstinence, the affective sensations expected from smoking are potentiated in more impulsive smokers (VanderVeen et al., 2008).

Most of the studies used standardized questionnaires or evaluated the physiological components related to the exposure of cigarette-related stimuli to estimate craving. The organic activation related to cue smoking exposure represents the anticipation and preparation for receive nicotine effects (Stewart et al., 1984). The measurement of the physiological response in cue-elicited craving is preferable, since it is less vulnerable to conscious control, has elevated ecological validity, and can provide additional information about the desire to smoke (Shiffman et al., 2013).

The literature that relates response inhibition, affectivity, and tobacco craving is scarce, so studies must con- 
sider methodologies of greater ecological validity, which can provide more consistent results for understanding the mechanisms associated with smoking maintenance. The effects of response inhibition - measured by the parametric Go/No-Go task, and affectivity - induced by a success-failure manipulation, on tobacco craving, elicited by smoking cues were examined. Therefore, this research aims to evaluate the interaction effects of response inhibition and affectivity in tobacco craving.

\section{MATERIALS AND METHODS}

\section{Study overview and participants}

The experiment was carried out from January 2019 until March 2020 in a sample of 90 students from the University of Guadalajara, 18 to 35 years old, who reported consuming five or more cigarettes a day. Participation in the study was voluntary and the sample was selected through a digital form. Participants were paired in terms of sex and age, that is, for each man, there was a woman of the same age. Exclusion criteria included consuming psychotropic substances, addiction to other psychoactive drugs, people diagnosed with heart disease (arrhythmia, uncontrolled blood pressure, etc.), and epilepsy. All participants were treated following APA ethical standards and the protocol was approved by the pertinent Institutional Review Board.

\section{Measures and Instrument}

Fagerstrom Test for Nicotine Dependence (FTND). It was used the Spanish version of the FTND (Becoña \& Vázquez, 1998) to assess nicotine dependence.

Questionnaire on Smoking Urges-brief (QSU-b). It was used the QSU-b (Cox et al., 2001) to estimate the level of tobacco craving.

Parametric Go/No-Go. It was used the task proposed by Langenecker et al. (2007), which consists of three levels, completed in order of ascending difficulty. For all three levels, it was presented a sequence of letters on a computer screen with 500 ms inter-stimuli interval. Responses should be made as quickly as possible with the fingers of the dominant hand, pressing the space bar on the computer keyboard each time the target letters " $r$ ", "s" and "t" (go) are presented, and not pressing it in the presence of the other letters (no-go).

Affective manipulation task. It was used an adapted version of the Digit Span Task (Woods et al., 2011). This task consists of remembering a sequence of digits (I-16) presented at random order, on a monitor, and participants were asked to type, on the computer keyboard, the numerical sequence saw. The task was modified to present feedback consistent with the responses issued and to play background music to facilitate the desired affective states.

Biofeedback. All physiological measures were recorded through biofeedback decoder model ProComp Infiniti (SA7500) brand Thought Technology Ltd, with BioGraph INFINITI software version 5.1.2. The sensors used were: a model photoplethysmography sensor (P/N:SA9308M) with a range of 2048 pulses/second to record heart rate; a sensor with hydrochloric silver - silver electrodes, with readings from $2 \mu \mathrm{S}$ (P/N:SA9309M) to record skin conductance; and a thermistor (P / N: SA9310M) with a range of $10^{\circ} \mathrm{C}$ to $45^{\circ} \mathrm{C}$ to record the distal temperature. Cooximeter. It was used the Smokerlyzer PiCO (Bedfont Scientific Ltd, Kent, U.K.) to evaluate the concentration of $\mathrm{CO}$ exhaled by the participants, to estimate the time of abstinence from tobacco.

\section{Procedures}

90 students were recruited from the University of Guadalajara, with voluntary participation. Participants were selected through a digital form and invited to attend the Behavioral Study and Research Center of the same university, to carry out the empirical phase of the study.

Pre-evaluation. All study participants signed a letter of consent and underwent a co-oximetry test. To participate in the study, individuals were required to have less than 10 ppm of expired CO, which corresponds to approximately eight hours of abstinence (Sandberg 2011). They then completed the smoking history questionnaires and the FTND. Subsequently, participants were divided into two groups of 45 participants according to performance on the parametric Go/No-Go task. A pilot study showed that regular smoking participants, who consume an average of six cigarettes a day, have an efficiency ratio of 14.11 (unpublished results). This Go/No-Go parameter is the most important measure of response inhibition and corresponds to the balance between response latency and accuracy, and is given by the following formula: efficiency rate $=$ overall accuracy/overall latency $\times 100$ (Langenecker et al., 2005). Therefore, the individuals who obtained an average lower than this value were located in the group "low response inhibition" (LRI), and those who showed a higher average were integrated into the group "high response inhibition" (HRI).

Phase 1. Participants were connected to biofeedback and went through a moment of rest, to obtain the baseline physiological parameters. Afterward, they underwent a craving facilitation session, in which they had to handle an unlit cigarette for three minutes without being able to consume it (Doran et al., 2009). Then, answered the QSU-b. 
Treatment. Participants in both experimental groups were randomly subdivided into two other groups: pleasant manipulation $(n=30)$ or unpleasant manipulation $(n=15)$. The affective manipulation task consisted of a digit task + music (Isen et al., 1978) or a rest session. For those who underwent the digit task, the number of digits presented was manipulated to provoke a better or worse performance for the participants and music consistent with the type of affective manipulation assigned: easy task + Rocky theme for the pleasant manipulation group and hard task + Russian under the Mongolian yoke for the unpleasant manipulation group (Västfjäll, 2002). For the participants who underwent the rest session, they were invited to close their eyes and relax as much as they could. After the affective facilitation established in this session, all the participants answered a question, scored from 1 to 10 , about the nature of the experience they had in this session.

Phase 2. The participants went to a new three-minute rest period, and then underwent another craving facilitation session, identical to the one they did in phase 1.

\section{Design and data analysis}

The experimental design of this study has a quantitative approach and it is of cross-sectional correlational type with a moderating variable. It is a $2 \times 2$ factorial design, with 15 replicas of craving for each group. The moderation procedure allows establishing under which circumstances one variable influences another, that is, the conditional or moderating effect of an independent variable on a dependent variable is explored. A moderation analysis was carried out to define in which circumstances (affective states as moderate variable M) the impulsive behavior, in terms of response inhibition (independent variable $X$ ), facilitates tobacco craving (dependent variable $Y$ ). In the simple moderation statistical model used (Figure 1) the main effect of $X$ was quantified by $\beta 1$, the main effect $M$ was quantified by $\beta 2$, and the interaction effect XM was estimated by $\beta 3$. In this study, it was analyzed whether the unstandardized coefficient $\beta 3$ was statistically significant, which indicated that the $X$ effect on Y depends on the values of M (Igartua, 2016). The IBM SPSS 25 statistical package was used for data analysis, in its test version, and the macro process was installed (Hayes, 2013).

The effect size was calculated employing eta-squared test (n2), in which $\eta 2=0.01$ indicates a small effect; $\eta 2$ $=0.06$ indicates a medium effect; $\eta 2=0.14$ indicates a large effect (Cohen, 1988).

The independent variable was categorical and classified participants into a high or low level of response inhibition, depending on the efficiency rate obtained in the parametric Go/No-Go task. Similarly, the moderator variable was categorical and segregated participants into pleasant or unpleasant affectivity. The dependent variable (craving) was weighted by physiological measures and the self-report questionnaire (QSU-b).

The physiologic phase 1 craving values were calculated by subtracting those obtained in the first craving facilitation session and the baseline values (craving assessment 1 - baseline); therefore, the indices correspond to the variability between these sessions. On the other hand, the craving of phase 2 was obtained by subtracting the rate of the second facilitation craving and the baseline (craving assessment 2 - baseline). The variability regarding self-reported craving was obtained by the difference between the second and first QSU-b scores.

Figure 1

Statistical diagram of simple moderation

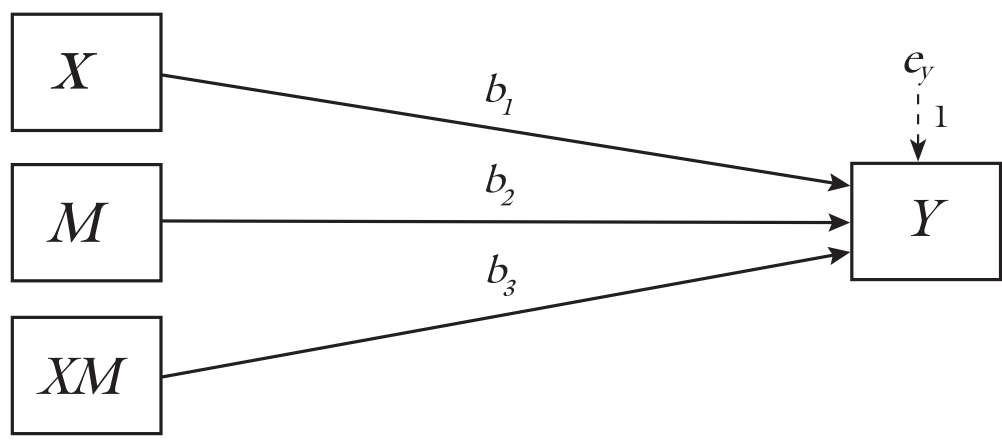

Source: Introduction to Mediation, Moderation, and Conditional Process Analysis. (p. 442). A. Hayes, 2013, the Guilford Press. 
Figure 2

Change of estimated marginal means on self-reported craving (QSU-b phase2 - QSU-b phase1)

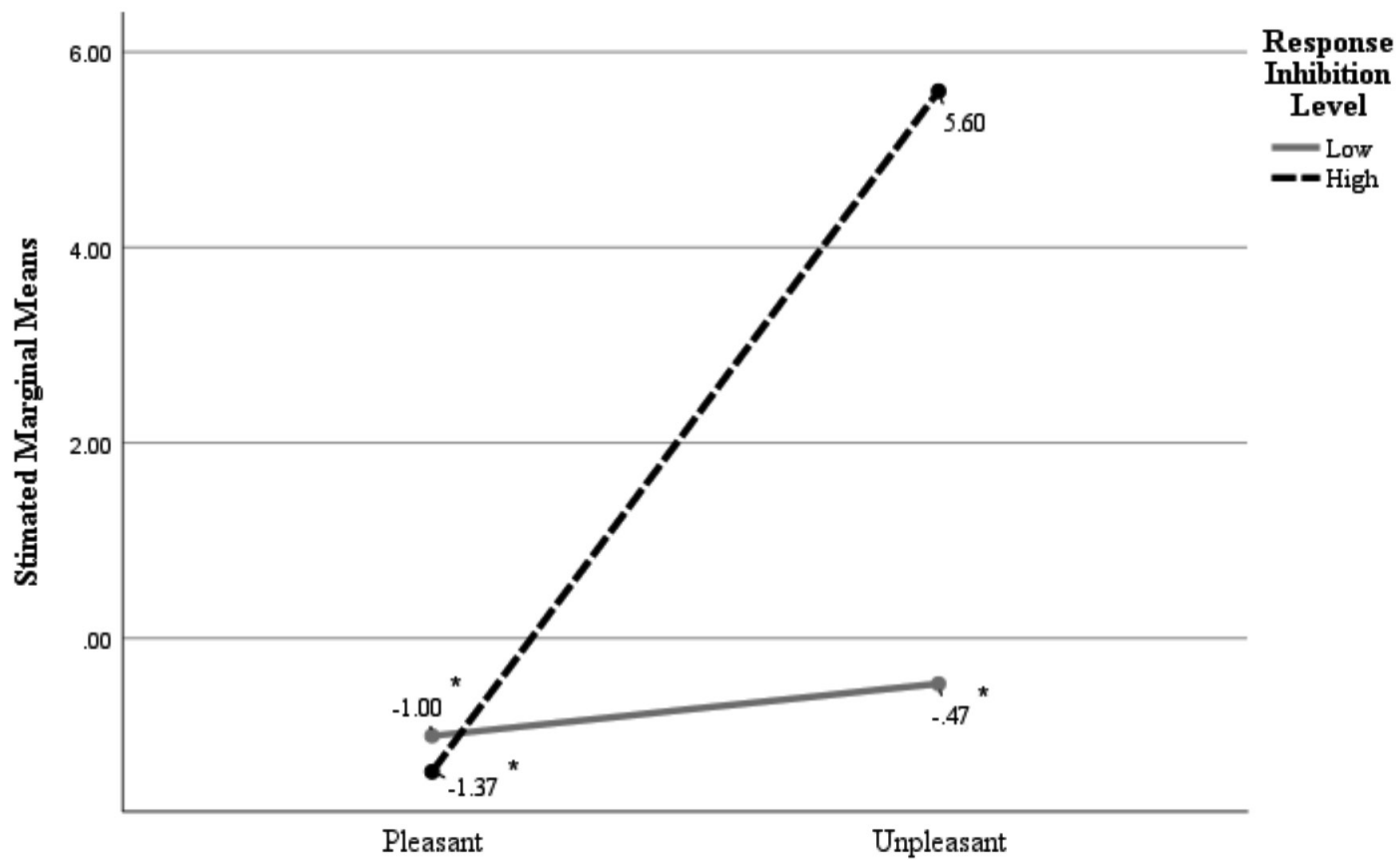

Note. Negative marginal mean values suggest that the self-reported craving responses before affective manipulation were higher than those after affective manipulation, implying a post-treatment reduction in craving.

There are no interaction effects of response inhibition and affectivity to generate changes in tobacco craving $(\beta 3=-.074, S E=1.538, p=.962)$ measured by heart rate. On the other hand, the results indicated a direct effect of the response inhibition and affective manipulation on the variability of craving $(\beta 1=2.153, S E=.870, p=$ $.006 ; \beta 2=2.933, S E=1.256, p=.009$, respectively). Participants with a high level of response inhibition had an increase in heart rate related to craving, independently of affectivity manipulation, and the increment for the high response inhibition group was statistically significant compared to the low response inhibition group (t $=3.672, p<.001)$. Unpleasant affectivity manipulation influenced the increase of heart rate related craving, regardless of response inhibition.

Figure 3 exhibits that for both affective manipulations, the HRI group shows higher marginal mean values of heart rate compared to the LRI group. Furthermore, the increase in heart rate related to craving is greater for those who have experienced unpleasant affective manipulation. These results imply that participants with a high level of response inhibition are more prone to feel a more robust craving on any kind of affectivity state.

There is a medium interaction effect of affectivity and response inhibition on the increase of tobacco craving mea- sured by the electrical skin conductance $(\beta 3=1.861, S E=$ $.773, p=.018, \eta 2=.063)$. Likewise, there are direct effects of response inhibition and affectivity on the craving measured by this physiological parameter $(\beta 1=1.812, S E=$ $.631, p=<.001$ and $\beta 2=.747, S E=.245, p=.051$, respectively). High-level response inhibition participants showed an increase in skin conductance related to craving, independently of affectivity manipulation. Unpleasant affectivity manipulation influences the increase of heart rate related craving, regardless of response inhibition.

Figure 4 shows that the HRI group is more reactive, from the perspective of electrical skin conductance to stimuli related to tobacco craving when experienced unpleasant affectivity. There are no differences in craving reactivity between groups when they experienced pleasant affective manipulations. These results suggested that participants with a high level of response inhibition are more prone to develop craving on unpleasant affectivity state.

There is no evidence of the interactive effect of affectivity and response inhibition on tobacco craving measured by limb temperature $(\beta 3=.594, S E=.717, p=$ .410). The results indicate that there are no direct effects of response inhibition, nor the types of affective manipulations in the variability of craving. 
Figure 3

Change of estimated marginal means on heart rate related to craving (HR phase2 - HR phase 1)

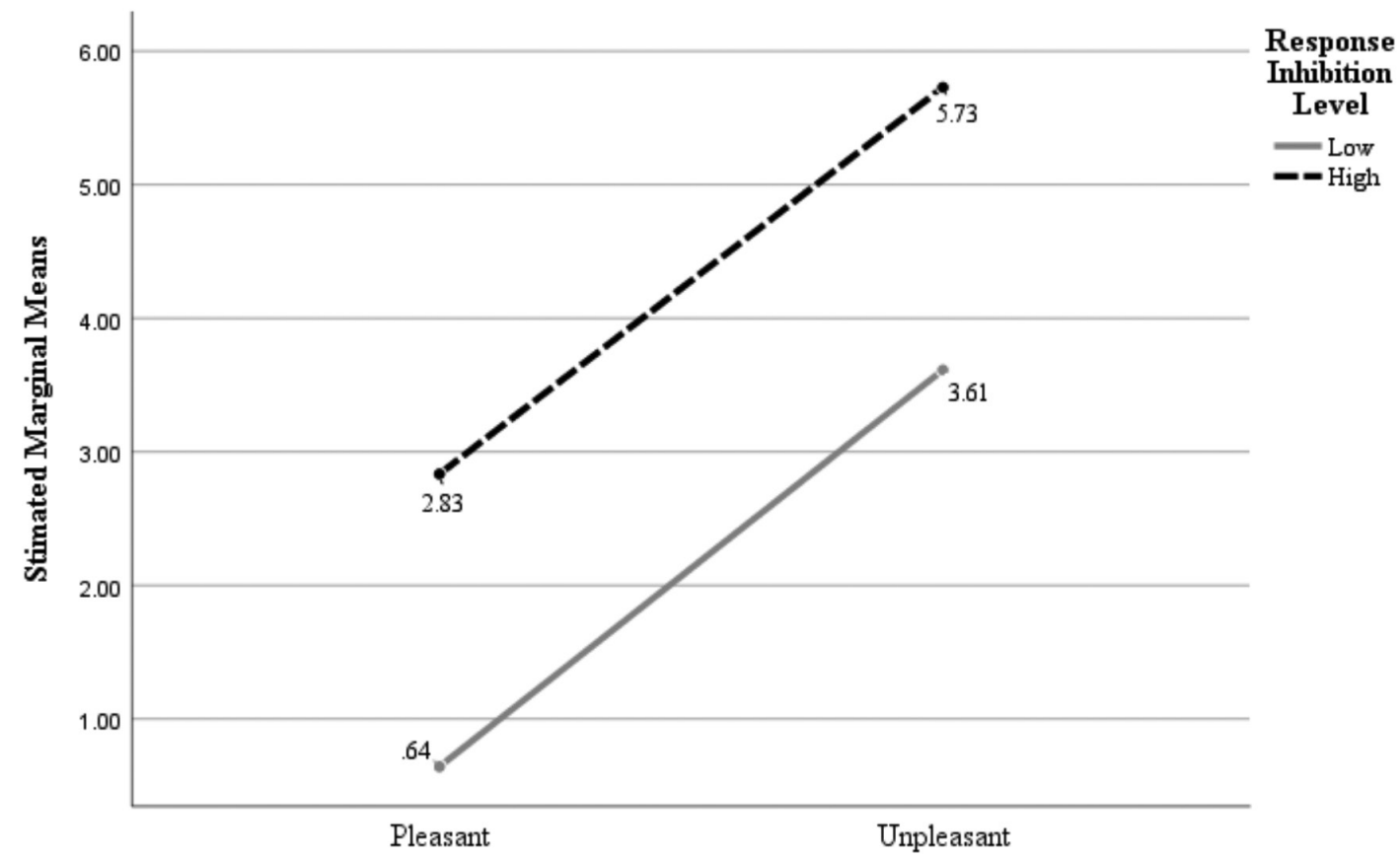

Figure 4

Change of estimated marginal means on skin conductance related to craving (SC phase2 - SC phase1)

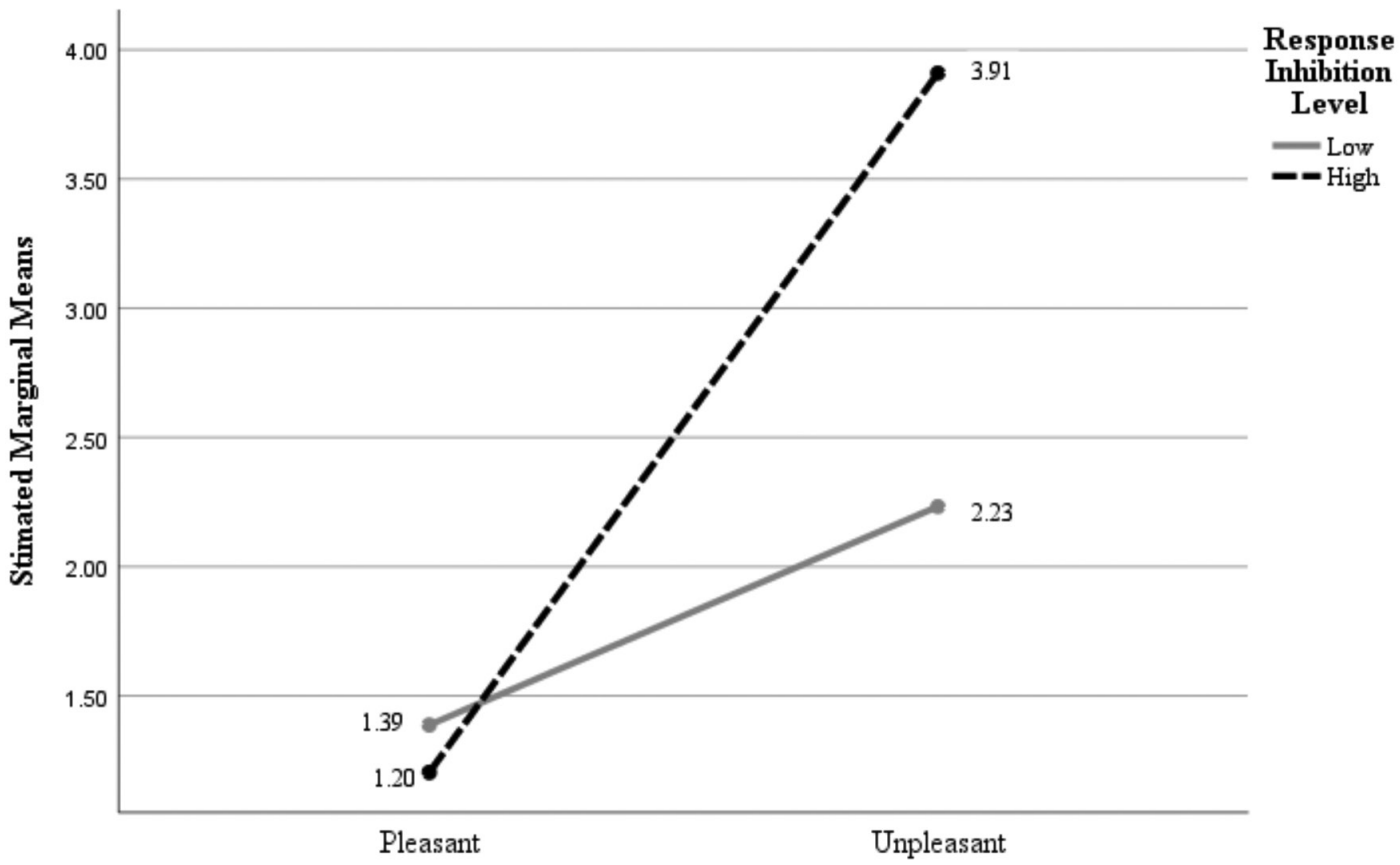




\section{DISCUSSION AND CONCLUSIONS}

The main objective of this research was to evaluate the interaction effects of affectivity and response inhibition on tobacco craving. The results suggest that the more impulsive smokers, who were subjected to unpleasant affective manipulations, had higher tobacco craving, measured by QSU-b and electrical skin conductance.

These findings corroborate the results obtained by various authors, in which, for the more impulsive smokers, unpleasant affect is a triggering factor for craving (Bares et al., 2018; Ditre et al., 2011; Doran et al., 2008; Shiyko et al., 2012; VanderVeen et al., 2008). Additionally, broaden the understanding of this relationship of variables because a methodology of greater ecological validity was used; in which response inhibition was measured by behavioral tests, and craving was generated by cue-reactivity paradigm and measured by physiological responses and self-report.

Another important finding was that smokers high in response inhibition showed a statistically significant increase in craving measured by changes in heart rate compared to less impulsive smokers. Ditre et al. (2011) suggest that the relationship between unpleasant affectivity and tobacco craving is sustained by negative reinforcement. They also propose that this process is understood as a classical conditioning model in which tobacco craving, associated with a withdrawal response to nicotine, is generalized to other unpleasant conditions, that serve as conditional stimuli to provoke the consumption desire. To the extent that individuals with a high level of response inhibition develop more negative reinforcement expectations than others, the unpleasant affect may induce a heightened increase in reported and physiological craving.

Impulsivity expressed under pleasant or unpleasant affective conditions are understood, respectively, in terms of positive and negative urgency; that causes hasty actions depending on the affectivity experienced (Whiteside \& Lynam, 2001). So, the results obtained support the congruence between the increase of negative urgency and the craving for tobacco measured by the self-report and the electrical skin conductance. It seems that this premise does not apply to positive urgency, since there was no integrative effect of response inhibition and pleasant affectivity in increasing the desire to smoke of any kind. Other studies that do not consider the influence of impulsivity, but only the effects of pleasant affectivity on craving changes, have found conflicting results. In some cases, the desire to consume the drug is increased (Dunbar et al., 2010 and Shiffman et al., 2014), and in others, there is no scientific evidence in the relation of variables (Shiffman et al., 2002 and Shiffman \& Waters, 2004).
Moon and Lee (2011) evaluated the association between sensitivity to rewards (a facet of impulsivity), pleasant affectivity, and tobacco craving. The results indicated a combined effect of impulsivity and positive affectivity on self-reported craving, but there was no interaction effect between impulsivity and positive affectivity on craving physiological responses. Our results are in line with the latter; however, the direct effect of impulsivity (in terms of response inhibition) and unpleasant affectivity on tobacco craving measured by heart rate and skin conductance were encountered. These discrepancies can be explained by the tobacco stimuli presentation method and affective manipulation process used. The literature suggests that in vivo are more effective than visual stimulations on cue-elicited craving paradigm (Drobes \& Tiffany, 1997). In addition, the combined affective manipulation method is superior to the isolated musical procedure (Westermann et al., 1996).

This study makes a contribution to the literature for using cue-eliciting craving paradigm and laboratory tasks to evaluate the relationship between response inhibition and tobacco craving, under affectivity conditions. However, some limitations have to be considered. Regarding the studied population, it is essential to highlight that the sample size by group of affective manipulation was limited and smokers had a low level of tobacco consumption pattern. It would be convenient that future studies were carried out with a larger population and different levels of tobacco consumption patterns.

Generalizations of the results are limited by the absence of neutral stimuli in experimentation. To broaden the findings presented, future studies could include, in addition to stimuli related to tobacco use, others of a neutral nature, to corroborate if the organic parameters correspond to craving or perception responses. The work carried out by Papachristou; Nederkoorn, Beunen et al. (2013) evidenced that chocolate craving is the result of a classic conditioning process, in which this behavior is acquired and extinguished (partially) by means of cues related to the substance. In addition, acquisition and extinction sessions could be included to analyze the influence of affective and impulsive interactions in these processes.

The results suggest that unpleasant affective manipulations modulate the relationship between response inhibition and tobacco craving, measured by QSU-b and electrical skin conductance. Response inhibition only exerts a direct effect on the desire for tobacco consumption when it is measured by heart rate, so unpleasant affectivity is a primary factor for the relationship between the variables. Understanding the relationship of the variables studied may have implications in rehabilitation interventions for smokers. It is essential to train or develop tech- 
niques to control the potential stimuli of negative affect, especially in those individuals with less capacity to inhibit responses. Thus, it is possible to increase resistance to craving and avoid tobacco consumption

\section{DISCLOSURE STATEMENT}

The authors declare that there is no conflict of interest.

\section{FUNDING}

This work was partially funded by National Council for Science and Technology - Conacyt, Mexico. Conacyt had no role in the study design, collection, analysis or interpretation of the data, writing the manuscript, or the decision to submit the paper for publication.

\section{REFERENCES}

Bares, C. B., Dick, D. M., \& Kendler, K. S. (2018). Nicotine dependence, internalizing symptoms, mood variability and daily tobacco use among young adult smokers. Addictive Behaviors, 83, 8794. doi: org/10.1016/j.addbeh.2017.09.004

Becoña, E., \& Vázquez, F. L. (1998). The Fagerström Test for Nicotine Dependence in a Spanish sample. Psychological Reports, 83(3Pt2), 1455-1458. doi: 10.2466/PR0.83.7.1455-1458

Borges, A. M., Leyro, T. M., Rosen, R. L., Zvolensky, M. J., \& Farris, S. G. (2019). Negative urgency and ad-libitum smoking topography. Drug and Alcohol Dependence, 201, 220-226. doi: 10.1016/j.drugalcdep.2019.04.021

Bujarski, S., Roche, D. J., Sheets, E. S., Krull, J. L., Guzman, I., \& Ray, L. A. (2015). Modeling naturalistic craving, withdrawal, and affect during early nicotine abstinence: A pilot ecological momentary assessment study. Experimental and Clinical Psychopharmacology, 23(2), 81-89. doi: 10.1037/a0038861

Cohen, J. (1988). Statistical Power Analysis for the Behavioral Sciences. Routledge Academic.

Cox, L., Tiffany, S. T., \& Christen, A. G. (2001). Evaluation of the brief questionnaire of smoking urges (QSU-brief) in laboratory and clinical settings. Nicotine Tobacco Research, 3(1), 7-16. doi: 10.1080/14622200020032051

Cyders, M. A., \& Coskunpinar, A. (2011). Measurement of constructs using self-report and behavioral lab tasks: is there overlap in nomothetic span and construct representation for impulsivity? Clinical Psychology Review, 31(6), 965-982. doi: 10.1016/j.cpr.2011.06.001

Ditre, J. W., Brandon, T. H., Zale, E. L., \& Meagher, M. M. (2011). Pain, nicotine, and smoking: Research findings and mechanistic considerations. Psychological Bulletin, 137(6), 1065-1093. doi: 10.1037/a0025544

Doran, N., Cook, J., McChargue, D., Myers, M., \& Spring, B. (2008). Cue-elicited negative affect in impulsive smokers. Psychology of addictive behaviors: Journal of the Society of Psychologists in Addictive Behaviors, 22(2), 249-256. doi: 10.1037/0893-164X.22.2.249
Doran, N., Cook, J., McChargue, D., \& Spring, B. (2009). Impulsivity and cigarette craving: differences across subtypes. Psychopharmacology, 207(3), 365-373. doi: 10.1007/s00213-009-1661-x

Doran, N., \& Tully, L. (2018). Impulsivity and tobacco product use over time. Addictive Behaviors, 85, 153-157. doi: 10.1016/j.addbeh.2018.06.007

Drobes, D.J., \& Tiffany, S.T. (1997). Induction of Smoking Urge Through Imaginal and In Vivo Procedures: Physiological and Self-Report Manifestations. Journal of Abnormal Psychology, 106(1), 15-25. doi: 10.1037/0021-843X.106.1.15

Dunbar, M. S., Scharf, D., Kirchner, T., \& Shiffman, S. (2010). Do smokers crave cigarettes in some smoking situations more than others? Situational correlates of craving when smoking. Nicotine \& Tobacco Research, 12(3), 226-234. doi: 10.1093/ntr/ntp198

Hayes, A. (2013). Introduction to Mediation, Moderation, and Conditional Process Analysis. The Guilford Press.

Heckman, B. W., Kovacs, M. A., Marquinez, N. S., Meltzer, L. R., Tsambarlis, M. E., Drobes, D. J., \& Brandon, T. H. (2013). Influence of affective manipulations on cigarette craving: A meta-analysis. Addiction, 108(12), 2068-2078. doi: 10.1111/add.12284

Igartua, J. (2016). Mediación, moderación y análisis de la mediación moderada con técnicas de bootstrapping. Universidad de Salamanca.

Isen, A. M., Clark, M., Shalker, T. E., \& Karp, L. (1978). Affect, accessibility of material in memory, and behavior: A cognitive loop? Journal of Personality and Social Psychology, 36(1), 11-12. doi: 10.1037/0022-3514.36.1.1

Kale, D., Pickering, A., \& Cooper, A. (2020). Examining the relationship between impulsivity-related personality traits and e-cigarette use in adults. Addictive Behaviors 106, 106348. doi: 10.1016/j. addbeh.2020.106348

Kale, D., Stautz, K., \& Cooper, A. (2018). Impulsivity related personality traits and cigarette smoking in adults: A meta-analysis using the UPPS-P model of impulsivity and reward sensitivity. Drug and Alcohol Dependence, 185, 149-167. doi: 10.1016/j.drugalcdep.2018.01.003

Karekla, M., Panayiotou, G., \& Collins, B. N. (2017). Predictors of urge to smoke under stressful conditions: An experimental investigation utilizing the PASAT-C task to induce negative affect in smokers. Psychology of Addictive Behaviors, 31(7), 735-743. doi: /10.1037/adb0000309

Langenecker, S. A., Bieliauskas, L. A., Rapport, L. J., Zubieta, J.-K., Wilde, E. A., \& Berent, S. (2005). Face emotion perception and executive functioning deficits in depression. Journal of Clinical and Experimental Neuropsychology, 27(3), 320-333. doi: 10.1080/13803390490490515720

Langenecker, S. A., Zubieta, J.-K., Young, E. A., Akil, H., \& Nielson, K. A. (2007). A task to manipulate attentional load, set-shifting, and inhibitory control: Convergent validity and test-retest reliability of the Parametric Go/No-Go Test. Journal of Clinical and Experimental Neuropsychology, 29(8), 842-853. doi 10.1080/13803390490490515720

Miller, E., Joseph, S., \& Tudway, J. (2004). Assessing the component structure of four self-report measures of impulsivity. Person- 
ality and Individual Differences, 37(2), 349-358. doi: 10.1016/j. paid.2003.09.008

Moon, J., \& Lee, J. (2011). Predicting cigarette-seeking behavior: How reward sensitivity and positive emotions influence nicotine cravings. Social Behavior and Personality, 39(6), 737-746. doi: 10.2224/sbp.2011.39.6.737

Papachristou, H., Nederkoorn, C., Havermans, R., Bongers, P., Beunen, S., \& Jansen, A. (2013). Higher levels of trait impulsiveness and a less effective response inhibition are linked to more intense cue-elicited craving for alcohol in alcoholdependent patients. Psychopharmacology, 228(4), 641-649. doi: 10.1007/ s00213-013-3063-3.

Papachristou, H., Nederkoorn, C., Beunen, S., \& Jansen, A. (2013). Dissection of appetitive conditioning. Does impulsivity play a role? Appetite, 69, 46-53. doi: 10.1016/j.appet.2013.05.011

Plewnia, C., Zwissler, B., Laengst, I., Maurer, B., Giel, K., \& Krueger, R. (2013). Effects of transcranial direct current stimulation (tDCS) on executive functions: Influence of COMT Val/Met polymorphism. Cortex, 49(7), 1801-1087. doi: 10.1016/j.cortex.2012.11.002

Roys, M., Weed,K., Carrigan, M., \& MacKillop, J. (2016). Associations between nicotine dependence, anhedonia, urgency and smoking motives. Addictive Behaviors, 62, 145-151. doi: 10.1016/j.addbeh.2016.06.002

Sandberg, A., Sköld, C. M., Grunewald, J., Eklund, A., \& Wheelock, $\AA$. M. (2011). Assessing recent smoking status by measuring exhaled carbon monoxide levels. PloS one, 6(12), e28864. doi: 10.1371/journal.pone.0028864

Shiffman, S., Dunbar, M., Kirchner, T., Li, X., Tindle, H., Anderson, S., \& Scholl, S. (2013). Smoker reactivity to cues: Effects on craving and on smoking behavior. Journal of Abnormal Psychology, 122(1), 264-280. doi: 10.1037/a0028339

Shiffman, S., Dunbar, M. S., Li, X., Scholl, S. M., Tindle, H. A., Anderson, S. J., \& Ferguson, S. G. (2014). Smoking patterns and stimulus control in intermittent and daily smokers. PLOS ONE, 9(3), e89911. doi: 10.1371/journal.pone.0089911

Shiffman, S., Gwaltney, C. J., Balabanis, M. H., Liu, K. S., Paty, J. A., Kassel, J. D., Hickcon, M., \& Gnys, M. (2002). Immediate antecedents of cigarette smoking: An analysis from ecological momentary assessment. Journal of Abnormal Psychology, 111(4), 531-545. doi: 10.1037/11855-015

Shiffman, S., \& Waters, A. J. (2004). Negative affect and smoking lapses: A prospective analysis. Journal of Consulting and Clinical Psychology, 72(2), 192-201. doi: 10.1037/0022-006X.72.2.192
Shiyko, M.P., Lanza, S.T., Tan, X., Li, R., \& Shiffman, S. (2012). Using the Time-Varying Effect Model (TVEM) to Examine Dynamic Associations between Negative Affect and Self Confidence on Smoking Urges: Differences between Successful Quitters and Relapsers. Prevention science, 13(3), 288-299. doi: 10.1007/ s11121-011-0264-z

Stewart, J., de Wit, H., \& Eikelboom, R. (1984). Role of unconditioned and conditioned drug effects in the self-administration of opiates and stimulants. Psychological Review, 91(2), 251-268. doi: 10.1037/0033-295X.91.2.251

Strickland, J. C., \& Johnson, M. W. (2021). Rejecting impulsivity as a psychological construct: A theoretical, empirical, and sociocultural argument. Psychological Review, 128(2), 336-361. doi: 10.1037/ rev0000263

VanderVeen, J. W., Cohen, L. M., Trotter, D. R., \& Collins, F. L. Jr. (2008). Impulsivity and the role of smoking related outcome expectancies among dependent college-aged cigarette smokers. Addictive Behaviors, 33(8), 1006-1011. doi: 10.1016/j.addbeh.2008.03.007

Västfjäll, D. (2002). Emotion induction through music: a review of the musical mood induction procedure. Musicae Scientiae, 5(1), 173-211. doi: 10.1177/10298649020050S107

Weidacker, K., Whiteford, S., Boy, F. \& Johnston, S. (2016). Response inhibition in the parametric Go/No-Go task and its relation to impulsivity and subclinical psychopathy. Quarterly Journal of Experimental Psychology, 70(3), 473-487. doi: 10.1080/17470218.2015.1135350

Westermann, R., Spies, K., Stahl, G., \& Hesse, F.W. (1996). Relative effectiveness and validity of mood induction procedures: a metaanalysis. European Journal of Social Psychology, 26(4), 557-580. doi: 10.1002/(SICI)1099-0992(199607)26:4<557::AIDEJSP769>3.0.CO;2-4

Whiteside, S. P., \& Lynam, D. R. (2001). The five factor model and impulsivity: using a structural model of personality to understand impulsivity. Personality and Individual Differences, 30(4), 669689. doi: 10.1016/S0191-8869(00)00064-7

Woods, D. L., Kishiyamaa, M. M., Lund, E. W., Herron, T. J., Edwards, B., Poliva, O., Hink, R. F., \& Reed, B. (2011). Improving digit span assessment of short-term verbal memory. Journal of Clinical and Experimental Neuropsychology, 33(1), 101-111. https://doi.org/10.10 80/13803395.2010.493149. doi: 10.1080/13803395.2010.493149 